\title{
Kinetic analysis of the hydrogen oxidation reaction at Nafion film covered Pt-black rotating disk electrodes
}

\author{
Ren-Bin Lin ${ }^{\mathrm{a}}$, Shin-Min Shih ${ }^{\mathrm{b}, *}$ \\ ${ }^{a}$ Department of Chemical Engineering, Chinese Culture University, Taipei 111, Taiwan \\ ${ }^{\mathrm{b}}$ Department of Chemical Engineering, National Taiwan University, No. 1, Section 4, Roosevelt Road, Taipei 106, Taiwan
}

Received 15 February 2008; received in revised form 14 May 2008; accepted 16 May 2008

\begin{abstract}
The kinetics of the $\mathrm{H}_{2}$ oxidation reaction at Nafion film covered Pt-black rotating disk electrodes (RDEs) in $0.5 \mathrm{M} \mathrm{H}_{2} \mathrm{SO}_{4}$ at $298 \mathrm{~K}$ was investigated by varying the $\mathrm{Pt}$ loading, Nafion film thickness, and rotating rate. The equation describing the $\mathrm{H}_{2}$ oxidation kinetics at an $\mathrm{RDE}$ with a Nafion film covered porous Pt layer was derived, assuming a Tafel-Volmer mechanism and taking into account the mass transfer resistances in the aqueous electrolyte, Nafion film, and Pt layer. The $\mathrm{H}_{2}$ oxidation reaction at the Pt layer was proved to be reversible and the measurable current density was determined entirely by the mass transfer of $\mathrm{H}_{2}$ in the aqueous electrolyte and the Nafion film; the apparent kinetic current density measured was due to the experimental error. More accurate results of kinetic analysis were obtained in this work than our results reported previously.
\end{abstract}

(C) 2008 Taiwan Institute of Chemical Engineers. Published by Elsevier B.V. All rights reserved.

Keywords: Pt-black; Nafion; Hydrogen oxidation; Rotating disk electrode; Fuel cell

\section{Introduction}

Fuel cell is a clean and efficient energy technology that converts chemical energy directly into electrical energy without emissions of air pollutants. Particularly, proton exchange membrane fuel cells (PEMFCs) have recently received more attention due to their high power density at relatively low temperatures (Kordesch and Simader, 1996; Ralph, 1997). The fuel $\left(\mathrm{H}_{2}\right)$ and oxidant $\left(\mathrm{O}_{2}\right.$ or air) gases are supplied to the anode and cathode of a fuel cell, respectively, and react with the aid of catalysts to produce electricity.

Platinum and Nafion respectively serve as the most widespread electrocatalyst and polymer electrolyte in lowtemperature fuel cells. Understanding the reaction kinetics at electrodes made of $\mathrm{Pt}$ and Nafion, including $\mathrm{H}_{2}$ oxidation and $\mathrm{O}_{2}$ reduction, is important to fuel cell design. Rotating disk electrode (RDE) is an effective means of studying the electrochemical reaction kinetics (Schmidt and Gasteiger, 2003). The hydrogen oxidation reaction kinetics at Nafion covered Pt-black or Pt on carbon electrodes has been studied by

\footnotetext{
* Corresponding author. Tel.: +8862 23633974; fax: +886223623040.

E-mail address: smshih@ntu.edu.tw (S.-M. Shih).
}

several investigators using the RDE technique under fuel cell relevant conditions (Lin and Shih, 2006a, 2007; Schmidt et al., 1998, 1999). For these electrodes, the catalyst powder is first immobilized on a rotating disk substrate and then the catalyst layer is coated with a Nafion film, forming a thin-layer electrode assembly similar to that used in fuel cells. Although these electrodes have a porous catalyst layer, the equation used to analyze the kinetics by the previous investigators is the Koutecky-Levich equation derived for a smooth Pt electrode (Bard and Faulkner, 2001).

The purpose of this work was to derive the equation appropriate for analyzing the hydrogen oxidation reaction kinetics at an RDE with a Nafion film covered porous Pt layer and reexamine our previous results obtained for Nafion film covered Pt-black RDEs (Lin and Shih, 2006a).

\section{Experimental}

\subsection{Materials}

A 5 wt.\% Nafion solution prepared by dissolving Nafion in the mixture of isopropanol and water (1100 EW, Ion Power) was used to recast the Nafion film. Pt-black (HiSPEC ${ }^{\mathrm{TM}} 1000$, Johnson Matthey) was used as the dispersed catalyst. Glassy 


\begin{tabular}{|c|c|}
\hline \multicolumn{2}{|c|}{ Nomenclature } \\
\hline$a$ & $\begin{array}{l}\text { active surface area per unit volume of catalyst } \\
\text { layer }(1 / \mathrm{cm})\end{array}$ \\
\hline$b$ & $=\exp (n F \eta / R T)$ \\
\hline$B$ & Levich constant $(\mathrm{mC} \mathrm{cm} / \mathrm{mol})$ \\
\hline$C$ & $\mathrm{H}_{2}$ concentration at catalyst surface $\left(\mathrm{mol} / \mathrm{cm}^{3}\right)$ \\
\hline$C_{\mathrm{f}}$ & $H C_{0}\left(\mathrm{~mol} / \mathrm{cm}^{3}\right)$ \\
\hline$C_{\mathrm{N}}$ & $\begin{array}{l}\mathrm{H}_{2} \text { concentration at aqueous electrolyte/Nafion } \\
\text { interface }\left(\mathrm{mol} / \mathrm{cm}^{3}\right)\end{array}$ \\
\hline$C_{\mathrm{S}}$ & $\begin{array}{l}\mathrm{H}_{2} \text { concentration at catalyst/Nafion interface } \\
\left(\mathrm{mol} / \mathrm{cm}^{3}\right)\end{array}$ \\
\hline$C_{0}$ & $\begin{array}{l}\mathrm{H}_{2} \text { concentration in the bulk of aqueous electro- } \\
\text { lyte }\left(\mathrm{mol} / \mathrm{cm}^{3}\right)\end{array}$ \\
\hline$D$ & $\mathrm{H}_{2}$ diffusivity in aqueous electrolyte $\left(\mathrm{cm}^{2} / \mathrm{s}\right)$ \\
\hline$D_{\mathrm{e}}$ & $\begin{array}{l}\text { effective diffusivity of } \mathrm{H}_{2} \text { in electrolyte filled } \\
\text { catalyst layer }\left(\mathrm{cm}^{2} / \mathrm{s}\right)\end{array}$ \\
\hline$D_{\mathrm{f}}$ & $\mathrm{H}_{2}$ diffusivity in polymer film $\left(\mathrm{cm}^{2} / \mathrm{s}\right)$ \\
\hline$F$ & Faraday constant $(96487 \mathrm{C} / \mathrm{mol})$ \\
\hline$H$ & $\begin{array}{l}\text { partition coefficient of } \mathrm{H}_{2} \text { between Nafion film } \\
\text { and aqueous electrolyte }\end{array}$ \\
\hline$i$ & local current density in catalyst layer $\left(\mathrm{mA} / \mathrm{cm}^{2}\right)$ \\
\hline$i_{\mathrm{k}}$ & kinetic current density $\left(\mathrm{mA} / \mathrm{cm}^{2}\right)$ \\
\hline$i_{1}$ & limiting current density $\left(\mathrm{mA} / \mathrm{cm}^{2}\right)$ \\
\hline$i_{\mathrm{m}}$ & measured current density $\left(\mathrm{mA} / \mathrm{cm}^{2}\right)$ \\
\hline$i_{0}$ & exchange current density $\left(\mathrm{mA} / \mathrm{cm}^{2}\right)$ \\
\hline$k_{\mathrm{m}}$ & $\begin{array}{l}\text { mass transfer coefficient in aqueous electrolyte } \\
(\mathrm{mA} \mathrm{cm} / \mathrm{mol})\end{array}$ \\
\hline$L$ & Nafion film thickness $(\mu \mathrm{m})$ \\
\hline$L_{\mathrm{c}}$ & catalyst layer thickness $(\mu \mathrm{m})$ \\
\hline$n$ & number of electrons involved in the reaction \\
\hline$R$ & gas constant $(8.314 \mathrm{~J} /(\mathrm{mol} \mathrm{K}))$ \\
\hline$T$ & absolute temperature $(\mathrm{K})$ \\
\hline$Y_{0}$ & Levich intercept $\left(\mathrm{cm}^{2} / \mathrm{mA}\right)$ \\
\hline$z$ & distance from the Nafion/catalyst interface $(\mu \mathrm{m})$ \\
\hline \multicolumn{2}{|c|}{ Greek symbols } \\
\hline$\delta$ & roughness factor of electrode surface \\
\hline$\varepsilon$ & effectiveness fac \\
\hline$\varepsilon_{1}$ & limiting value of effectiveness factor \\
\hline$\eta$ & overpotential (mV) \\
\hline & $\begin{array}{l}\text { equilibrium coverage of catalyst surface by } \\
\text { hydrogen at } i=0\end{array}$ \\
\hline & kinematic viscosity $\left(\mathrm{cm}^{2} / \mathrm{s}\right)$ \\
\hline & Thiele modulus \\
\hline & limiting value of Thiele modulus \\
\hline & rotation rate (rpm) \\
\hline
\end{tabular}

carbon (GC) disk electrode (disk area $=0.1963 \mathrm{~cm}^{2}$ and shroud area $=1.131 \mathrm{~cm}^{2}$, Pine Instruments) was served as the substrate for the deposition of the catalyst. The disk was polished with a $0.05 \mu \mathrm{m}$ alumina powder (CHI Instruments) before use. The electrolyte was $0.5 \mathrm{M} \mathrm{H}_{2} \mathrm{SO}_{4}$ solution prepared form concentrated sulfuric acid (J.T. Baker) and ultrapure water (18 M $\Omega$, Millipore). High purity $\mathrm{H}_{2}$ gas $(99.999 \%$, San$\mathrm{Fu}$ ) was used.

\subsection{Thin-film electrode preparation}

Aqueous catalyst suspensions of $1-2 \mathrm{mg} / \mathrm{mL}$ were prepared by mixing $25-50 \mathrm{mg}$ of Pt-black and $25 \mathrm{~mL}$ of deionized water under ultrasonication for about $10 \mathrm{~min}$. A volume of $15-20 \mu \mathrm{L}$ of the catalyst suspension was pipetted onto the GC disk surface. The deposit was dried at room temperature for about $1.5 \mathrm{~h}$ and then at $70{ }^{\circ} \mathrm{C}$ for $30 \mathrm{~min}$. After the catalyst layer was dry, $20 \mu \mathrm{L}$ of Nafion solution was put on its top. Subsequent annealing at $70{ }^{\circ} \mathrm{C}$ in a vacuum oven was made for at least $40 \mathrm{~min}$ to evaporate the residual solvent in the resulting thin-film electrode. This annealing treatment renders the Nafion film insoluble and with sufficient strength to bind the catalyst particles (Zook and Leddy, 1996). The concentration of Nafion solution was varied by diluting the $5 \mathrm{wt} . \%$ Nafion solution with isopropanol to yield recast films with thicknesses ranged from 0.1 to $8.0 \mu \mathrm{m}$. The film thickness was calculated from the mass and the surface area of the recast film, assuming a dry Nafion density of $1.98 \mathrm{~g} / \mathrm{cm}^{3}$ (Watanabe et al., 1995; Zook and Leddy, 1996). About $90 \%$ of the shroud area was found to be covered by the Nafion coating, thus the geometric surface area of the film was estimated to be $1.0 \mathrm{~cm}^{2}$. The film thickness was further measured using a surface texture profilometer (Dektak 3030, Sloan Technology), and the difference between the measured and calculated values was about $6 \%$.

\subsection{Electrochemical experiments}

The rotating disk electrode was housed in a conventional three-compartment glass cell with a saturated calomel reference electrode (SCE) and a Pt foil counter electrode. The electrochemical behavior of an electrode was measured using a potentiostat (Autolab PGSTAT30, Ecochemie) with a computer-controlled general purpose electrochemical system (GPES). Throughout this study, all potentials were referred to the reversible hydrogen electrode (RHE) scale.

Before starting the electrochemical measurement, the electrode was immersed for $8-10 \mathrm{~h}$ in deaerated $0.5 \mathrm{M}$ $\mathrm{H}_{2} \mathrm{SO}_{4}$ solution, which exhibited a very similar $\mathrm{pH}$ value to that of the Nafion film. Characteristic cyclic voltammogram (CV) for an electrode in deaerated $0.5 \mathrm{M} \mathrm{H}_{2} \mathrm{SO}_{4}$ was obtained after cycling the potential of the electrode between 0 and $1.2 \mathrm{~V}$ vs. RHE for $1 \mathrm{~h}$ (Lin and Shih, 2006b). This long run-in period was necessary to obtain stable and reproducible data.

Experiments for the $\mathrm{H}_{2}$ oxidation reaction at an electrode were performed by rotating the electrode immersed in $\mathrm{H}_{2}$ saturated $0.5 \mathrm{M} \mathrm{H} \mathrm{H}_{2} \mathrm{SO}_{4}$ solution at room temperature $\left(25 \pm 1{ }^{\circ} \mathrm{C}\right)$. The rotation rates were in the range from 400 to $3600 \mathrm{rpm} . \mathrm{H}_{2}$ was passed through the solution for $40 \mathrm{~min}$ before the experiment started and above the solution during the experiment. The potential of the electrode was changed between 0 and $0.4 \mathrm{~V}$ vs. RHE at a scan rate of $5 \mathrm{mV} / \mathrm{s}$. 


\section{Results and discussion}

\subsection{Experimental results of $\mathrm{H}_{2}$ oxidation reaction}

The $\mathrm{H}_{2}$ oxidation reaction was studied using electrodes for which the Pt-black loading varied from 76 to $204 \mu \mathrm{g} / \mathrm{cm}^{2}$ and the Nafion film thickness varied from 0.1 to $8.0 \mu \mathrm{m}$. The voltammograms for some electrodes are represented in Fig. 1. One can see that the current density, $i_{\mathrm{m}}$, increases with increasing overpotential, $\eta$, and reaches a limiting value when the overpotential is about $70 \mathrm{mV}$ vs. RHE. At the same overpotential, the current density increases with increasing rotation rate and is larger when the Nafion film is thinner at the same rotation rate. As seen in Fig. 1(a), the increase in Pt loading did not cause the current density to change accordingly and significantly at each rotation rate; therefore, the variations of the current density were due to the experimental errors. The variations of the limiting current density were about \pm 0.04 to $\pm 0.12 \mathrm{~mA} / \mathrm{cm}^{2}$ from the mean as the rotation rate was increased from 400 to $3600 \mathrm{rpm}$. The experimental errors are thought to arise mainly from the uncertainty in the measurement of the Nafion film thickness. Moreover, as shown
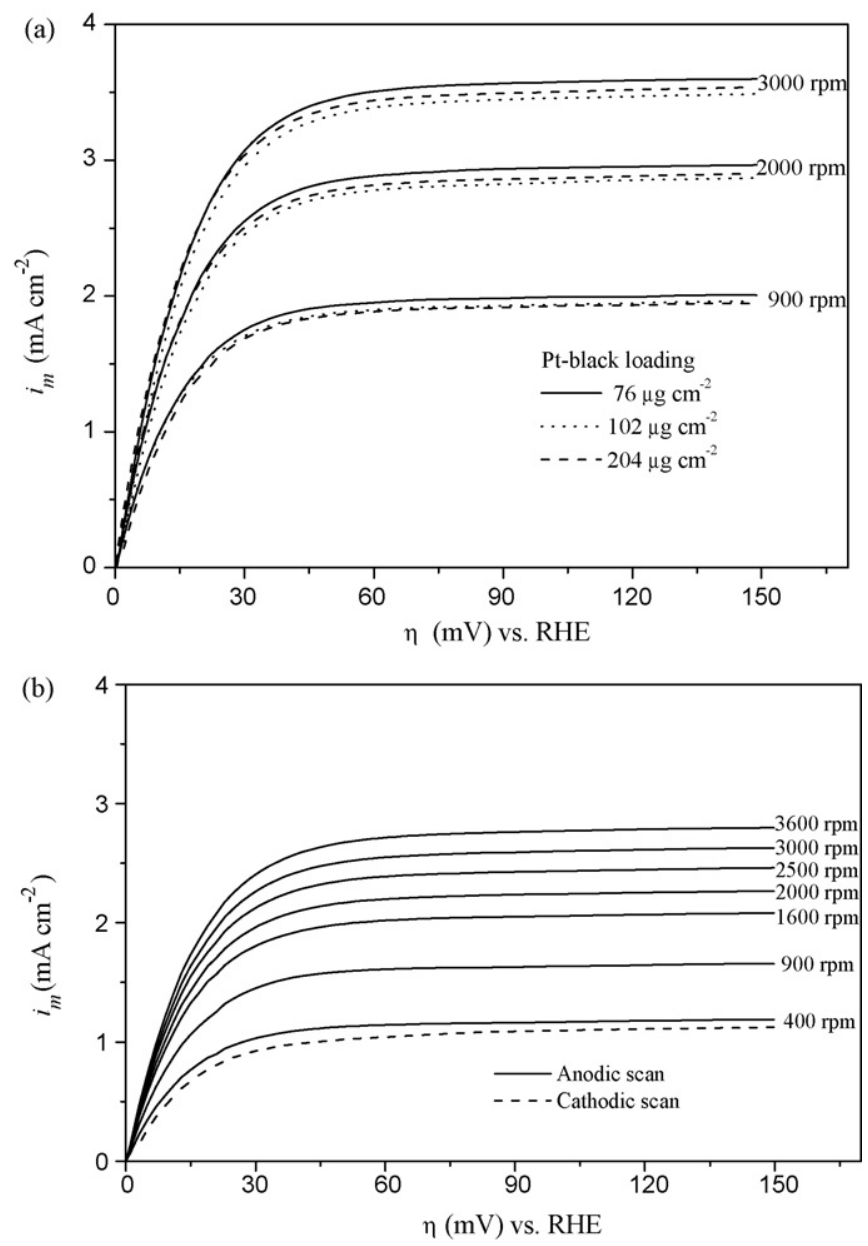

Fig. 1. Hydrodynamic voltammograms for $\mathrm{H}_{2}$ oxidation at the Nafion film covered Pt-black electrodes with the film thicknesses of (a) $0.2 \mu \mathrm{m}$ (Pt-black loading: 76-204 $\mu \mathrm{g} / \mathrm{cm}^{2}$ ) and (b) $4.0 \mu \mathrm{m}$ (Pt-black loading: $102 \mu \mathrm{g} / \mathrm{cm}^{2}$ ) in $\mathrm{H}_{2^{-}}$ saturated $0.5 \mathrm{M} \mathrm{H}_{2} \mathrm{SO}_{4}$ electrolyte. Scan rate: $5 \mathrm{mV} / \mathrm{s}$. in Fig. 1(b), the hysteresis of $\mathrm{H}_{2}$ oxidation currents between the anodic and cathodic scans caused by the double layer capacitance was minute (about $0.07 \mathrm{~mA} / \mathrm{cm}^{2}$ at $0.15 \mathrm{~V}$ vs. RHE). Anodic voltammograms obtained were analyzed in this study.

\subsection{Equations for kinetic analysis}

Vogel et al. (1975) have studied the $\mathrm{H}_{2}$ oxidation reaction on Pt electrocatalysts in acid solutions. They found that the reaction follows the Tafel-Volmer sequence,

$\mathrm{H}_{2}+2 \mathrm{M} \rightleftarrows 2 \mathrm{MH} \quad$ (Tafel)

$2 \mathrm{MH} \rightleftarrows 2 \mathrm{M}+2 \mathrm{H}^{+}+2 \mathrm{e}^{-} \quad$ (Volmer)

with the dissociation reaction (Tafel) rate controlling.

According to their derivation, the local current density, $i$, in the catalyst layer can be written as

$i=\frac{i_{0} \mathrm{e}^{2 F \eta / R T}}{C_{0}}\left[\frac{1}{\theta_{0}+\left(1-\theta_{0}\right) \mathrm{e}^{F \eta / R T}}\right]^{2}\left(C-\frac{C_{0}}{\mathrm{e}^{2 F \eta / R T}}\right)$

where $i_{0}$ is the exchange current per unit catalyst surface area, $F$ is the Faraday constant, $\eta$ is the overpotential, $R$ is the gas constant, $T$ is the absolute temperature, $\theta_{0}$ is the equilibrium coverage of the catalyst surface by hydrogen at $i=0$; and $C$ and $C_{0}$ are the hydrogen concentrations at the catalyst surface and in the bulk of the aqueous electrolyte, respectively.

For $\mathrm{H}_{2}$ oxidation at an RDE with a Nafion film covered catalyst layer, $\mathrm{H}_{2}$ molecules in the bulk of the aqueous electrolyte must move to the Nafion film surface, permeate through the Nafion film, and then diffuse into the pores of the catalyst layer before they react on the Pt particle surface. Therefore, the mass transfer resistances in the aqueous electrolyte, Nafion film, and catalyst layer should be taken into account.

The diffusional effect of $\mathrm{H}_{2}$ on the overall reaction rate of the catalyst layer can be represented by the effectiveness factor, $\varepsilon$, which is the ratio of the rate affected by the diffusion of $\mathrm{H}_{2}$ in the catalyst layer to that unaffected. According to Stonehart and Ross (1976),

$\varepsilon=\frac{\tanh \Phi}{\Phi}$

where

$\Phi=L_{\mathrm{c}}\left(\frac{a i_{0} b}{2 F C_{0} D_{\mathrm{e}}}\right)^{1 / 2}\left[\frac{1}{\theta_{0}+\left(1-\theta_{0}\right) b^{1 / 2}}\right]$

and $L_{\mathrm{c}}$ is the thickness of catalyst layer, $a$ is the active surface area per unit volume of catalyst layer, $D_{\mathrm{e}}$ is the effective diffusivity of $\mathrm{H}_{2}$ in the electrolyte filled catalyst layer, and $b=\exp (2 F \eta / R T)$.

Assuming steady state, the overall reaction rate of $\mathrm{H}_{2}$ at the catalyst layer, the mass transfer rate of $\mathrm{H}_{2}$ through the Nafion film, and the mass transfer rate of $\mathrm{H}_{2}$ from the bulk of the electrolyte to the Nafion film surface are equal. In this case, the current density based on the electrode geometric area, $i_{\mathrm{m}}$, can 
be written as

$$
\begin{aligned}
i_{\mathrm{m}} & =\frac{\varepsilon \delta i_{0} b}{C_{0}}\left[\frac{1}{\theta_{0}+\left(1-\theta_{0}\right) b^{1 / 2}}\right]^{2}\left(C_{\mathrm{s}}-\frac{C_{0}}{b}\right) \\
& =\frac{n F D_{\mathrm{f}} H}{L}\left(C_{\mathrm{N}}-C_{\mathrm{s}}\right)=n F k_{\mathrm{m}}\left(C_{0}-C_{\mathrm{N}}\right)
\end{aligned}
$$

where $\delta$ is the roughness factor, which is the ratio of the total catalyst surface area to the electrode geometric area; $C_{\mathrm{s}}$ and $C_{\mathrm{N}}$ are the $\mathrm{H}_{2}$ aqueous-phase concentrations at the catalyst/Nafion and the aqueous electrolyte/Nafion interfaces, respectively; $n$ is the number of electrons $(=2)$ involved in the electrode reaction; $D_{\mathrm{f}}$ is the diffusivity of $\mathrm{H}_{2}$ in the Nafion film; $H$ is the partition coefficient of $\mathrm{H}_{2}$ between the Nafion film and the aqueous electrolyte; $L$ is the thickness of the Nafion film; and $k_{\mathrm{m}}$ is the liquid-phase mass transfer coefficient of $\mathrm{H}_{2}$. For an RDE, $n F k_{\mathrm{m}}$ is given by (Bard and Faulkner, 2001)

$n F k_{\mathrm{m}}=0.62 n F D^{2 / 3} v^{-1 / 6} \omega^{1 / 2}=B \omega^{1 / 2}$

where $D$ is the reactant diffusivity in the electrolyte, $v$ is the electrolyte kinematic viscosity, and $\omega$ is the rotation rate. It should be noted that $\varepsilon$ or $\Phi$ is not a function of $C_{\mathrm{s}}$ (see Appendix A) and is not affected by the presence of the mass transfer resistances in the Nafion film and aqueous electrolyte.

The relations expressed by Eq. (4) can be rearranged to give an equation similar to the Koutecky-Levich equation (Bard and Faulkner, 2001),

$$
\begin{aligned}
\frac{1}{i_{\mathrm{m}}}= & \left(\frac{b}{b-1}\right) \\
& \times\left\{\frac{1}{\varepsilon \delta i_{0} b /\left[\theta_{0}+\left(1-\theta_{0}\right) b^{1 / 2}\right]^{2}}+\frac{1}{n F D_{\mathrm{f}} C_{\mathrm{f}} / L}+\frac{1}{B C_{0} \omega^{1 / 2}}\right\}
\end{aligned}
$$

where $C_{\mathrm{f}}=H C_{0}$. Eq. (6) is also applicable to smooth Pt RDEs by letting $\varepsilon=1$; in this case, the term $\delta i_{0} b\left[\theta_{0}+\left(1-\theta_{0}\right) b^{1 / 2}\right]^{-2}$ is called the kinetic current density.

As seen from the above equation, when $\eta$ is large enough, $i_{\mathrm{m}}$ reaches the limiting value, $i_{1}$, given by

$\frac{1}{i_{1}}=\frac{1}{\varepsilon_{1} \delta i_{0} /\left(1-\theta_{0}\right)^{2}}+\frac{1}{n F D_{\mathrm{f}} C_{\mathrm{f}} / L}+\frac{1}{B C_{0} \omega^{1 / 2}}$

where $\varepsilon_{1}$ is the limiting value of $\varepsilon$ when $\Phi$ reaches $\Phi_{1}$ at large enough $\eta ; \Phi_{1}$ is given by

$\Phi_{1}=L_{\mathrm{c}}\left[\frac{a i_{0}}{2 F C_{0} D_{\mathrm{e}}\left(1-\theta_{0}\right)^{2}}\right]^{1 / 2}$

If $\Phi_{1} \gg 1$, Eq. (2) reduces to

$\varepsilon_{1}=\Phi_{1}^{-1}$

and the denominator of the first term of Eq. (7) becomes

$\varepsilon_{1} \delta i_{0}\left(1-\theta_{0}\right)^{-2}=\left(2 F C_{0} D_{\mathrm{e}} a i_{0}\right)^{1 / 2}\left(1-\theta_{0}\right)^{-1}$

Therefore, when $\Phi_{1} \gg 1, i_{1}$ is independent of $L_{\mathrm{c}}$ or the $\mathrm{Pt}$ loading provided $a$ is kept constant.
Eq. (7) shows that a plot of $1 / i_{\mathrm{m}}$ vs. $\omega^{-1 / 2}$ at a sufficiently high overpotential is a straight line with a slope of $1 / B C_{0}$ and an intercept, $Y_{0}$, corresponding to

$Y_{0}=\frac{1}{\varepsilon_{1} \delta i_{0} /\left(1-\theta_{0}\right)^{2}}+\frac{L}{n F D_{\mathrm{f}} C_{\mathrm{f}}}$

According to Eq. (11), the values of $D_{\mathrm{f}} C_{\mathrm{f}}$ and $\varepsilon_{1} \delta i_{0}\left(1-\theta_{0}\right)^{-2}$ can be determined by plotting $Y_{0}$ vs. $L$.

If the $\mathrm{H}_{2}$ oxidation reaction is very rapid, i.e., $\varepsilon \delta i_{0} \rightarrow \infty$, Eqs. (6) and (7) become

$\frac{1}{i_{\mathrm{m}}}=\left(\frac{b}{b-1}\right) \frac{1}{i_{1}}$

$\frac{1}{i_{1}}=\frac{1}{n F C_{\mathrm{f}} D_{\mathrm{f}} / L}+\frac{1}{B C_{0} \omega^{1 / 2}}$

Eq. (12) can be rearranged to give

$\mathrm{e}^{-2 \mathrm{~F} \eta / R T}=1-\frac{i_{\mathrm{m}}}{i_{1}}$

or

$\eta=\frac{-2.303 R T}{2 F} \log \left(1-\frac{i_{\mathrm{m}}}{i_{1}}\right)$

Therefore, a plot of $\eta$ vs. $\log \left[\left(i_{1}-i_{\mathrm{m}}\right) / i_{1}\right]$ will yield a straight line with a zero intercept and a slope of $-2.303 R T / 2 F$, no matter what Pt loading, rotation rate, and Nafion film thickness are used.

\subsection{Estimation of kinetic parameters}

Fig. 2 shows the plots of $\log \left[\left(i_{1}-i_{\mathrm{m}}\right) / i_{1}\right]$ vs. $\eta$. One can see that the plots are linear and nearly coincide for different rotation rates and Nafion film thicknesses. The inverse of the slope of the plot was found to be $-34.8 \pm 1.5 \mathrm{mV} / \mathrm{dec}$ in average, which is in good agreement with the theoretical value $(-30 \mathrm{mV} / \mathrm{dec}$ at $25{ }^{\circ} \mathrm{C}$ ) given by Eq. (15). This result indicates that the $\mathrm{H}_{2}$ oxidation reaction at the catalyst layer was very facile, or a socalled reversible reaction (Bard and Faulkner, 2001), and the oxidation rate was entirely controlled by the mass transfer of $\mathrm{H}_{2}$ in the aqueous electrolyte and the Nafion film. This result also explains why the current density was unaffected by the $\mathrm{Pt}$ loading. Mello and Ticianelli (1997) have reported that the $\mathrm{H}_{2}$ oxidation reaction at bare and Nafion covered smooth Pt RDEs in $0.5-0.01 \mathrm{M} \mathrm{H}_{2} \mathrm{SO}_{4}$ solutions is reversible. Because the roughness factors of our electrodes (which is about 23 for $76 \mu \mathrm{g} / \mathrm{cm}^{2} \mathrm{Pt}$ loading) are much greater than that of a smooth $\mathrm{Pt}$ electrode, the $\mathrm{H}_{2}$ oxidation reaction at our electrodes must be reversible also.

The $i_{\mathrm{m}}^{-1}$ vs. $\omega^{-1 / 2}$ plots for different Nafion film thicknesses at $\eta=100 \mathrm{mV}$ are shown in Fig. 3. These plots are linear and parallel to each other. The slopes of the lines are $1 / B C_{0}$ according to Eq. (7). The average value of $B C_{0}$ obtained from the line slopes is $(6.68 \pm 0.09) \times 10^{-2} \mathrm{~mA} /\left(\mathrm{cm}^{2} \mathrm{rpm}^{1 / 2}\right)$. This $B C_{0}$ value is in excellent agreement with that, $6.54 \times 10^{-2} \mathrm{~mA} /\left(\mathrm{cm}^{2} \mathrm{rpm}^{1 / 2}\right)$, calculated by Gasteiger et al. 

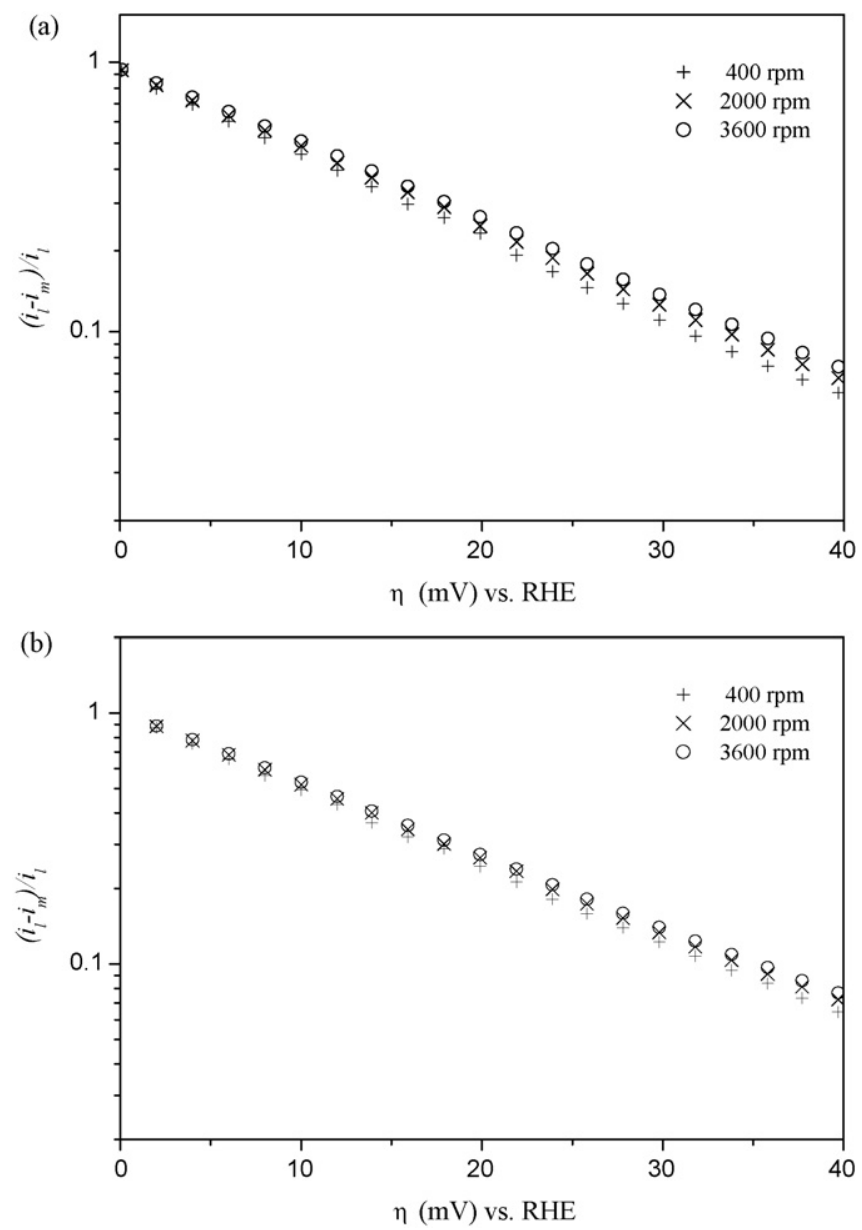

Fig. 2. Mass transfer corrected Tafel plots for $\mathrm{H}_{2}$ oxidation at the Nafion film covered Pt-black electrodes (Pt-black loading: $102 \mu \mathrm{g} / \mathrm{cm}^{2}$ ) with the film thickness of (a) $0.2 \mu \mathrm{m}$ and (b) $8.0 \mu \mathrm{m}$ in $\mathrm{H}_{2}$-saturated $0.5 \mathrm{M} \mathrm{H}_{2} \mathrm{SO}_{4}$ electrolyte.

(1995) at $25^{\circ} \mathrm{C}$, using $n=2, \quad D=3.7 \times 10^{-5} \mathrm{~cm}^{2} / \mathrm{s}$, $v=1.07 \times 10^{-2} \mathrm{~cm}^{2} / \mathrm{s}$, and $C_{0}=7.14 \times 10^{-4} \mathrm{M}$ (their original $C_{0}$ value should be corrected by dividing by 10$)$.

The intercepts $\left(Y_{0}\right)$ obtained from the $i_{\mathrm{m}}^{-1}$ vs. $\omega^{-1 / 2}$ plots at $\eta=400 \mathrm{mV}$ are plotted in Fig. 4 as a function of $L$. One can see

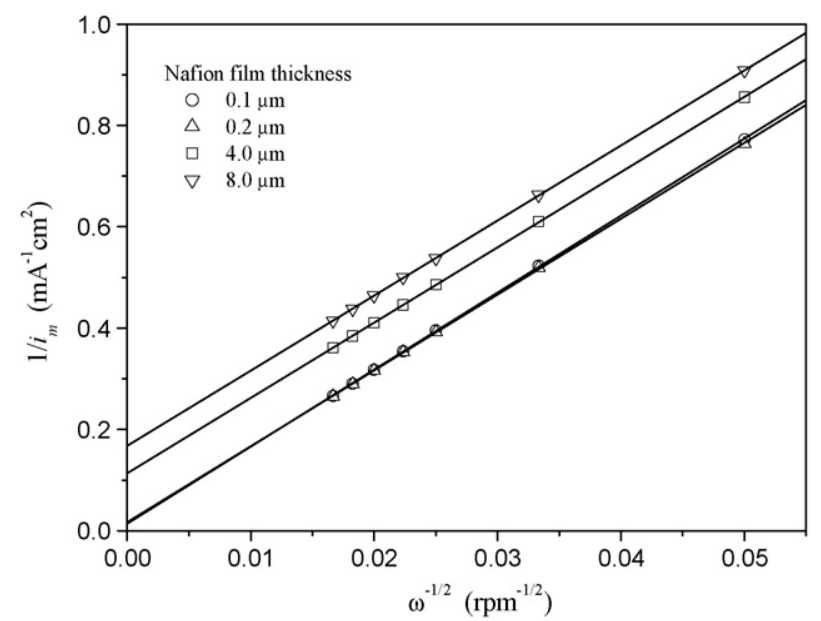

Fig. 3. Koutecky-Levich plots for $\mathrm{H}_{2}$ oxidation at $\eta=100 \mathrm{mV}$ at the Nafion film covered Pt-black electrodes (Pt-black loading: $102 \mu \mathrm{g} / \mathrm{cm}^{2}$ ) with various film thicknesses.

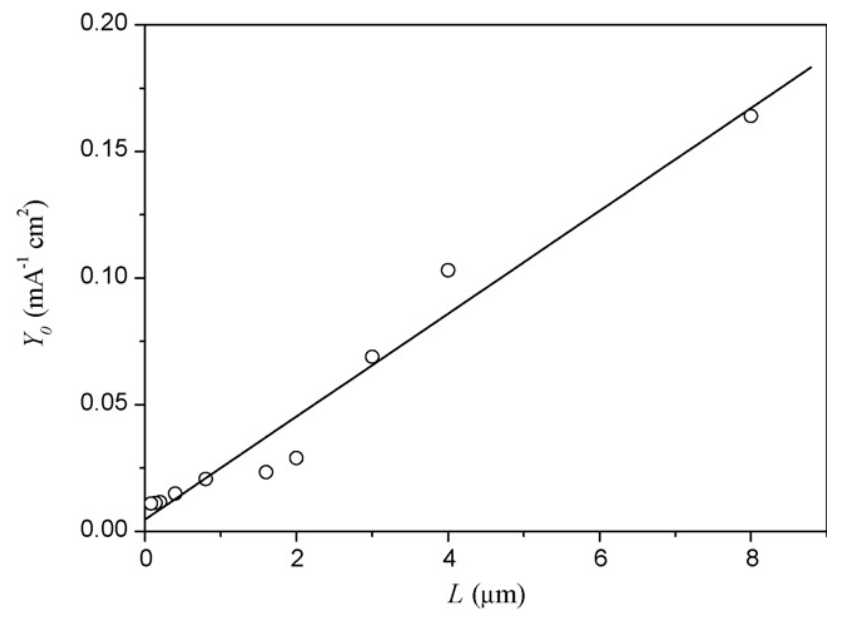

Fig. 4. $Y_{0}$ vs. $L$ plots for $\mathrm{H}_{2}$ oxidation at $\eta=400 \mathrm{mV}$ at the Nafion film covered Pt-black electrodes (Pt-black loading: $102 \mu \mathrm{g} / \mathrm{cm}^{2}$ ) with various film thicknesses.

that $Y_{0}$ data approach to a small positive value, about $0.011 \mathrm{~cm}^{2} / \mathrm{mA}$, when $L \leq 0.2 \mu \mathrm{m}$. The inverse of this $Y_{0}$ value, about $90 \mathrm{~mA} / \mathrm{cm}^{2}$, was taken as the value of the kinetic current density, $i_{\mathrm{k}}$, in our previous work (Lin and Shih, 2006a). However, because the $\mathrm{H}_{2}$ oxidation reaction is reversible, $Y_{0}$ should be zero when $L$ is zero according to Eq. (11). Therefore, the small $Y_{0}$ value at $L \leq 0.2 \mu \mathrm{m}$ are considered to be due to the error in $Y_{0}$ estimated. This explanation was confirmed by the error analysis of the estimated value of $Y_{0}$ at $L=0$. The linear regression of the data in Fig. 4 using Eq. (11) gave a value of $Y_{0}$ at $L=0$ of $0.0047 \mathrm{~cm}^{2} / \mathrm{mA}$ and its standard error of $0.0042 \mathrm{~cm}^{2} / \mathrm{mA}$. The $95 \%$ confidence interval of $Y_{0}$ at $L=0$ was calculated to be $0.0047 \pm 0.0098 \mathrm{~cm}^{2} / \mathrm{mA}$. This confidence interval reveals that the true value of $Y_{0}$ at $L=0$ is essentially zero because $Y_{0}$ cannot be negative.

Some previous investigators (Schmidt et al., 1998; Schmidt and Gasteiger, 2003; Watanabe et al., 1995) also obtained small $Y_{0}$ values for the $\mathrm{H}_{2}$ oxidation reaction at Pt electrodes with or without a very thin Nafion film at high overpotentials. Their corresponding $i_{\mathrm{k}}$ values range from 40 to $60 \mathrm{~mA} / \mathrm{cm}^{2}$. Watanabe et al. (1995) attributed their $i_{\mathrm{k}}$ values to some rate-limiting chemical process. However, Schmidt and Gasteiger (2003) attributed the $i_{\mathrm{k}}$ values to the error in $Y_{0}$ estimated and the residual resistance due to the thin Nafion film.

The slope of the linear regression line in Fig. 4 gave a $D_{\mathrm{f}} C_{\mathrm{f}}$ value of $(2.6 \pm 0.2) \times 10^{-11} \mathrm{~mol} /(\mathrm{cm} \mathrm{s})$ according to Eq. (11); this $D_{\mathrm{f}} C_{\mathrm{f}}$ value is very close to that, $2.4 \times 10^{-11} \mathrm{~mol} /(\mathrm{cm} \mathrm{s})$, obtained when zero intercept was assumed. This $D_{\mathrm{f}} C_{\mathrm{f}}$ value is considered to be more accurate than that, $5.2 \times 10^{-11}$ $\mathrm{mol} /(\mathrm{cm} \mathrm{s})$, obtained previously by the nonlinear regression of the $Y_{0}^{-1}$ vs. $L^{-1}$ data (Lin and Shih, 2006a), because the linear regression method gave a $Y_{0}$ value at $L=0$ very close to that should be for the reversible $\mathrm{H}_{2}$ oxidation reaction.

The $D_{\mathrm{f}} C_{\mathrm{f}}$ value determined is close to the product of the hydrogen solubility, $C_{0}$, and diffusivity, $D$, in $0.5 \mathrm{M} \mathrm{H}_{2} \mathrm{SO}_{4}$ mentioned previously or reported by Mello and Ticianelli (1997) $\left(0.59 \times 10^{-6} \mathrm{~mol} / \mathrm{cm}^{3}\right.$ and $3.8 \times 10^{-5} \mathrm{~cm}^{2} / \mathrm{s}$, respectively), but is higher than the values for recast Nafion films 
reported in literatures (Maruyama et al., 1998; Mello and Ticianelli, 1997; Watanabe et al., 1995). For instance, a $D_{\mathrm{f}} C_{\mathrm{f}}$ value of $9.0 \times 10^{-12} \mathrm{~mol} /(\mathrm{cm} \mathrm{s})$ for those immersed in $0.5 \mathrm{M}$ $\mathrm{H}_{2} \mathrm{SO}_{4}$ was reported by Mello and Ticianelli (1997). The discrepancy in the $D_{\mathrm{f}} C_{\mathrm{f}}$ values reported can be explained partly by the errors in the experimental measurements, especially in the estimation of the film thickness, and the different methods of data treatment. Furthermore, the structural properties of the Nafion film, such as the pore size and the distribution of the hydrophilic and hydrophobic phases, are known to affect the $D_{\mathrm{f}} C_{\mathrm{f}}$ value significantly (Gottesfeld et al., 1987; Zook and Leddy, 1996). It should be noted that the Nafion films prepared in this study are much thinner than those used by the previous authors.

Because the $\mathrm{H}_{2}$ oxidation reaction is reversible, the value of $i_{0}$ cannot be determined in this work. The values of $i_{0}$ reported in the literature, however, vary markedly. Vogel et al. (1975) reported that $i_{0}$ values for smooth $\mathrm{Pt}$, Pt black, and Pt on carbon are of no difference, about $22 \mathrm{~mA} / \mathrm{cm}^{2}$ in $96 \mathrm{wt} \% \mathrm{HClO}_{4}$ at $22{ }^{\circ} \mathrm{C}$. A value of $1.62 \mathrm{~mA} / \mathrm{cm}^{2}$ was reported by Markovic et al. (1997) for a Nafion coated smooth Pt electrode in $0.1 \mathrm{M} \mathrm{HClO}_{4}$. A value of $0.25 \mathrm{~mA} / \mathrm{cm}^{2}$ was obtained by Jiang and Kucernak (2004) for their porous $\mathrm{Pt}$ microelectrodes in $0.5 \mathrm{M} \mathrm{H}_{2} \mathrm{SO}_{4}$ at 293 K. Markovic et al. (1997) found that the $i_{0}$ for the $\mathrm{H}_{2}$ oxidation on $\mathrm{Pt}$ is unique with respect to the crystal surfaces. From their results obtained in $0.05 \mathrm{M} \mathrm{H}_{2} \mathrm{SO}_{4}$, the $i_{0}$ values on $\mathrm{Pt}$ (1 10 ), Pt (1 000$)$, and Pt (1 111$)$ surfaces at $298 \mathrm{~K}$ were estimated to be $0.92,0.55$, and $0.40 \mathrm{~mA} / \mathrm{cm}^{2}$, respectively. One of the possible reasons for this great variation of $i_{0}$ value is that the electrochemical reaction itself is so rapid that the mass transfer resistance is relatively much greater than the electrochemical reaction resistance and, therefore, $i_{0}$ cannot be determined or accurately determined. In order to obtain accurate $i_{0}$ value for the $\mathrm{H}_{2}$ oxidation reaction on $\mathrm{Pt}$ by using the RDE technique, the catalyst surface area per unit volume of catalyst layer, $a$, should be made very small.

For electrodes used in this study, the kinetics of $\mathrm{H}_{2}$ oxidation reaction can be described by Eqs. (12) and (13). The $i_{\mathrm{m}}$ values calculated using Eqs. (12) and (13) and the parameters estimated were in good agreement with measured values; the differences between the calculated and measured $i_{1}$ values were less than $10 \%$.

\section{Conclusion}

The kinetics of the hydrogen oxidation reaction at Nafion film covered Pt-black RDEs in $0.5 \mathrm{M} \mathrm{H}_{2} \mathrm{SO}_{4}$ at $298 \mathrm{~K}$ was investigated. The equation describing the $\mathrm{H}_{2}$ oxidation kinetics at an RDE with a Nafion film covered porous Pt layer was derived, assuming a Tafel-Volmer mechanism and taking into account the mass transfer resistances in the aqueous electrolyte, Nafion film, and Pt layer. The hydrogen oxidation reaction at the Pt layer was proved to be reversible and the measurable current density was determined entirely by the mass transfer of hydrogen in the aqueous electrolyte and the Nafion film. The apparent kinetic current densities measured were due to experimental errors. The $D_{\mathrm{f}} C_{\mathrm{f}}$ value obtained for Nafion films was affected by the method of data treatment; the value obtained in this work is considered to be more accurate than that reported in the previous work (Lin and Shih, 2006a). In order to obtain accurate exchange current density by using the RDE technique, the Pt surface area per unit volume of Pt layer should be made very small.

\section{Acknowledgements}

The authors would like to express sincere appreciation to the National Science Council (Taiwan) for the financial support. We also thank Ms. Li-Chen Cheng for the kind assistance.

\section{Appendix A}

For $\mathrm{H}_{2}$ oxidation at a Nafion covered catalyst layer RDE immersed in acid solution, the diffusion of $\mathrm{H}_{2}$ in the catalyst layer can be described by the following equations:

$D_{\mathrm{e}} \frac{\mathrm{d}^{2} C}{\mathrm{~d} z^{2}}-\frac{a i}{2 F}=0$

$C=C_{\mathrm{s}} \quad$ at $\quad z=0$

$\frac{\mathrm{d} C}{\mathrm{~d} z}=0 \quad$ at $\quad z=L_{\mathrm{c}}$

where $z$ is the distance from the Nafion/catalyst interface and the other symbols have the same meanings as in the text. The expression of $i$ is given by Eq. (1). Eqs. (A-1)-(A-3) can be solved to give the concentration profile:

$\frac{\left(C / C_{0}\right)-1 / b}{\left(C_{\mathrm{s}} / C_{0}\right)-1 / b}=\frac{\cosh \left[\Phi\left(1-\left(z / L_{\mathrm{c}}\right)\right)\right]}{\cosh \Phi}$

where $\Phi$ is given by Eq. (3).

From the definition of $\varepsilon$,

$\varepsilon=\frac{\int_{0}^{L_{\mathrm{c}}}\left(C-\left(C_{0} / b\right)\right) \mathrm{d} z}{\left(C_{\mathrm{s}}-\left(C_{0} / b\right)\right) L_{\mathrm{c}}}=\frac{\tanh \Phi}{\Phi}$

Therefore, $\varepsilon$ is not a function of $C_{\mathrm{s}}$, and is the same as that obtained with $C_{\mathrm{s}}=C_{0}$.

The measurable electrode current density is given by

$i_{\mathrm{m}}=\left.2 F D_{\mathrm{e}} \frac{\mathrm{d} C}{\mathrm{~d} z}\right|_{z=0}=2 F D_{\mathrm{e}} C_{0}\left(\frac{C_{\mathrm{s}}}{C_{0}}-\frac{1}{b}\right)\left(\frac{\Phi}{L_{\mathrm{c}}}\right) \tanh \Phi$

Combining with Eqs. (A-5) and (3), Eq. (A-6) can be expressed in terms of $\varepsilon$ :

$i_{\mathrm{m}}=\frac{\varepsilon \delta i_{0} b}{C_{0}}\left[\frac{1}{\theta_{0}+\left(1-\theta_{0}\right) b^{1 / 2}}\right]^{2}\left(C_{\mathrm{s}}-\frac{C_{0}}{b}\right)$

When the mass transfer resistances in the Nafion film and the aqueous electrolyte are absent, $C_{\mathrm{s}}$ is equal to $C_{0}$, and Eq. (A-6) or (A-7) reduces to that given by Stonehart and Ross (1976).

\section{References}

Bard, A. J. and L. R. Faulkner, Electrochemical Methods-Fundamentals and Applications, Wiley, New York, U.S.A. (2001). 
Gasteiger, H. A., N. M. Markovic, and P. N. Ross, " $\mathrm{H}_{2}$ and CO Electrooxidation on Well-Characterized Pt, Ru, and Pt-Ru. 1. Rotating Disk Electrode Studies of the Pure Gases Including Temperature Effects," J. Phys. Chem., 99, 8290 (1995).

Gottesfeld, S., I. D. Raistrick, and S. Srinivasan, "Oxygen Reduction Kinetics on a Platinum RDE Coated with a Recast Nafion Film," J. Electrochem. Soc., 134, 1455 (1987).

Jiang, J. H. and A. Kucernak, "Investigation of Fuel Cell Reactions at the Composite Microelectrode/Solid Polymer Electrolyte Interface. I. Hydrogen Oxidation at the Nanostructured Pt/Nafion Membrane Interface," $J$. Electroanal. Chem., 567, 123 (2004).

Kordesch, K. and G. Simader, Fuel Cells and their Applications, VCH, New York, U.S.A. (1996).

Lin, R. B. and S. M. Shih, "Kinetic Analysis of the Hydrogen Oxidation Reaction on Pt-Black/Nafion Electrode," J. Solid State Electrochem., 10, 243 (2006a)

Lin, R. B. and S. M. Shih, "Cyclic Voltammetric Measurement of Catalyst Surface Area for Pt-Black/Nafion Electrodes," J. Chin. Inst. Chem. Engrs., 37, 1 (2006b).

Lin, R. B. and S. M. Shih, "Kinetics of Hydrogen Oxidation Reaction on Nafion-Coated Pt/C Electrodes under High Overpotentials," J. Chin. Inst. Chem. Engrs., 38, 365 (2007).

Markovic, N. M., B. N. Grgur, and P. N. Ross, "Temperature-Dependent Hydrogen Electrochemistry on Platinum Low-Index Single-Crystal Surface in Acid Solutions," J. Phys. Chem., 101, 5405 (1997).

Maruyama, J., M. Inaba, K. Katakura, Z. Ogumi, and Z. Takehara, "Influence of Nafion Film on the Kinetics of Anodic Hydrogen Oxidation," $J$. Electroanal. Chem., 447, 201 (1998).
Mello, R. M. Q. and E. A. Ticianelli, "Kinetic Study of the Hydrogen Oxidation Reaction on Platinum and Nafion Covered Platinum Electrodes," Electrochim. Acta, 42, 1031 (1997).

Ralph, T. R., "Proton Exchange Membrane Fuel Cells: Progress in Cost Reduction of the Key Components," Platinum Metals Rev., 41, 102 (1997).

Schmidt, T. J., H. A. Gasteiger, G. D. Stab, P. M. Urban, D. M. Kolb, and R. J. Behm, "Characterization of High-Surface-Area Electrocatalysts Using a Rotating Disk Electrode Configuration," J. Electrochem. Soc., 145, 2354 (1998).

Schmidt, T. J., H. A. Gasteiger, and R. J. Behm, "Rotating Disk Electrode Measurements on the CO Tolerance of a High-Surface-Area Pt/Vulcan Carbon Fuel Cell Catalyst,"' J. Electrochem. Soc., 146, 1296 (1999).

Schmidt, T. J. and H. A. Gasteiger, "Rotating Thin-Film Method for Supported Catalysts," Handbook of Fuel Cells-Fundamentals, Technology and Applications, Vol. 2, p. 316, Vielstich, W., H. A. Gasteiger, and A. Lamm (Eds.), John Wiley \& Sons, U.S.A. (2003).

Stonehart, P. and P. Ross, "The Use of Porous Electrodes to Obtain Kinetic Rate Constants for Rapid Reactions and Adsorption Isotherms of Poisons," Electrochim. Acta, 21, 441 (1976).

Vogel, W., J. Lundquist, P. Ross, and P. Stonehart, "The Rate Controlling Step for Electrochemical Oxidation of Hydrogen on Pt in Acid and Poisoning of the Reaction by CO,' Electrochim. Acta, 20, 79 (1975).

Watanabe, M., H. Igarashi, and K. Yosioka, "An Experimental Prediction of the Preparation Condition of Nafion-Coated Catalyst Layers for PEFCs," Electrochim. Acta, 40, 329 (1995).

Zook, L. A. and J. Leddy, "Density and Solubility of Nafion: Recast, Annealed, and Commercial Films," Anal. Chem., 68, 3793 (1996). 